\title{
A Rare Case of Docetaxel-Induced Hydrocephalus Presenting with Gait Disturbances Mimicking and Coexisting with Taxane-Associated Polyneuropathy: The Relevance of Differential Diagnosis, Clinical Assessment, and Response to Ventriculoperitoneal Shunt
}

\author{
Lucas Ezequiel Serrano Sponton ${ }^{a} \quad$ Elke Januschek ${ }^{b}$ \\ aDepartment of Neurosurgery, Mainz University Hospital, Mainz, Germany; ${ }^{b}$ Department \\ of Neurosurgery, Offenbach Hospital, Offenbach am Main, Germany
}

\section{Keywords}

Docetaxel · Hydrocephalus · Gait disturbances · Polyneuropathy

\begin{abstract}
Docetaxel constitutes a widely used chemotherapeutic agent as a first-line treatment for several neoplastic diseases. One of the most common side effects induced by this drug is polyneuropathy, which among other symptoms can cause gait disbalance. However, in exceptional cases gait disturbances could be related to docetaxel-induced hydrocephalus, a rare event that up to the present has been overseen throughout the medical literature and
\end{abstract}




\section{Case Reports in Oncology}

should be meticulously differentiated from polyneuropathy, since its clinical features, treatment, and prognosis differ drastically. We present the case of a woman with a progressive gait disturbance that started immediately after having been treated with docetaxel for breast cancer resembling the same clinical characteristics as seen in patients affected by normal pressure hydrocephalus. The symptoms had been observed for about 2 years as having been caused only by polyneuropathy, given the high incidence of this side effect and the accompanying numbness of distal extremities. However, brain MRI evidenced a marked enlargement of the ventricular system. Brain metastases as well as carcinomatous meningitis were ruled out. After having placed a ventriculoperitoneal shunt, the patient showed a rapid, longlasting and outstanding improvement of gait performance. We discuss the coexistence, in this case, of taxane-associated hydrocephalus and polyneuropathy and describe the clinical features, assessment and surgical outcome of docetaxel-induced hydrocephalus, since its early recognition and differentiation from the highly frequent taxane-associated polyneuropathy has relevant consequences for the management and treatment of these patients.

(C) 2017 The Author(s)

Published by S. Karger AG, Basel

\section{Introduction}

Docetaxel constitutes one of the standard chemotherapeutic agents used in newly diagnosed breast cancer [1]. Although nervous system toxicity is one of the most common adverse effects described for this drug, affecting about $20-58 \%$ of patients, the far most common expression of this toxicity is polyneuropathy, which can be severe in up to $6 \%$ of cases [2]. The occurrence of hydrocephalus in patients receiving taxanes, like docetaxel or paclitaxel, constitutes an extreme uncommon feature and clinical presentation, prognosis, and response to shunting techniques have not been systematically studied in the literature up to the present. To our knowledge, there are no reports in peer review journals about this rare complication of docetaxel therapy. We present the case of a patient with progressive gait disturbances after having been treated with docetaxel for breast cancer and whose symptomatology had been misinterpreted and linked only to taxane-associated polyneuropathy. Brain MRI scans revealed, however, a marked hydrocephalus. After having ruled out meningeal spread, the patient was treated with a ventriculoperitoneal shunt, experiencing a clear and long-lasting improvement of gait performance after surgery. We discuss the clinical features of this case and provide recommendations regarding assessment, differential diagnosis, and treatment of this rare side effect of docetaxel.

\section{Case Report}

A 64-year-old woman presented due to chronic progressive gait disturbances that had started approximately 1 month after concluding a 4-cycle docetaxel-based chemotherapy for breast cancer 2 years ago. Prior to chemotherapy, the patient was able to walk normally. Almost at the same time, the patient reported to have started with a light numbness of the extremities, accentuated distally, a symptom that had remained stable during those 2 years. 
She did not complain about other neurological symptoms like headache, dizziness, speech, attention or concentration difficulties, memory or sight loss, abnormal movements or bladder/bowel disturbances. The patient was regularly followed by her oncologist and up to the present there had been no evidence of cancer relapse.

In the first instance, the gait disorder was assumed to be due a docetaxel-induced polyneuropathy, given the high frequency of this side effect associated with the treatment with this drug and the accompanying extremity numbness [3]. Electrophysiological studies were performed later on and, although inconclusive, confirmed the presence of polyneuropathy. However, despite the clinical stability of the sensory deficits, the patient had experienced a continuous and dramatic progression of her gait disturbance and was therefore referred to a neurologist.

At the moment of consultation, the patient presented a gait disorder characterized by small steps, rotation instability, and an increment in sustentation base. The Romberg test was negative, although there was objectively a light impairment of deep and superficial sensory input in both feet and hands. The patient had otherwise normal cranial nerve function and deep muscular reflexes, there were no signs of pyramidal tract affection, and urinary or bowel sphincter function was retained. There was no evidence of tremor, freezing or cogwheel phenomenon. Regarding cognitive performance, Mini-Mental State Examination and verbal fluency tests revealed normal scores.

Brain MRI revealed a marked hydrocephalus with a dramatic enlargement of the supraand infratentorial ventricular system and no cortical atrophy (Fig. 1). Furthermore, there was no evidence of malignant brain or meningeal seed.

We decided to perform a lumbar puncture to drain $30 \mathrm{~mL}$ of cerebrospinal fluid (CSF) and gait performance was assessed prior and $24 \mathrm{~h}$ after the puncture. A $10-\mathrm{m}$ walking test revealed a clear reduction in the number of steps as well as time required to complete the task between the pre- and post-puncture measures. Additionally, the patient reduced the number of steps needed for a $360^{\circ}$ rotation after puncture (Table 1). Cytology of CSF was otherwise inconspicuous.

Based on these results, we decided to place a ventriculoperitoneal shunt. The surgery was performed following a standard technique using a pro-GAV ${ }^{\circledR}$ system with an adjustable valve (labeled at $8 \mathrm{~cm} \mathrm{H}_{2} \mathrm{O}$ ) and a gravitational component fixed at $20 \mathrm{~cm} \mathrm{H}_{2} \mathrm{O}$. The patient recovered successfully from the surgery and did not experience postoperative complications. Improvement on gait performance observed after CSF drainage remained stable immediately after surgery and during the follow-up (at the moment 38 months), despite the unchanged numbness of arms and legs.

\section{Discussion}

Hydrocephalus represents an extremely rare event after treatment with taxanes and there is a lack of reports in the medical literature regarding clinical presentation, assessment, differential diagnosis and outcome after surgery. According to our online search, of about 13,223 patients reported by the Food and Drug Administration (FDA) to have experienced severe side effects after receiving docetaxel, only $20(0.15 \%)$ cases of hydrocephalus have been recorded [4]. Hydrocephalus is even rarer after treatment with the other widely 


\section{Case Reports in Oncology}

used taxane, paclitaxel. Up to the present, there have only been 4 cases of hydrocephalus in patients receiving paclitaxel reported by the FDA according to online databases (comprising $0.02 \%$ of among 14,615 adverse effect reports) [5].

On the other hand, polyneuropathy constitutes the most common side effect following treatment with taxanes [2]. Since both polyneuropathy and hydrocephalus can lead to gait disturbances, the awareness and differential diagnosis becomes of high relevance, since the treatment and prognosis of both side effects differ significantly [3]. While polyneuropathy may be refractory to therapy [3], patients with hydrocephalus can clearly benefit from a ventriculoperitoneal shunt. In our patient, the gait disorder observed did not resemble a typical steppage polyneuropathic gait, but it was rather characterized by small steps and enlarged sustentation base and rotational difficulties, all features observed classically in patients with normal pressure hydrocephalus (NPH) [6, 7]. Furthermore, although typical polyneuropathic sensory deficits in our patient had remained stable, NPH-like gait disbalance had followed a continuous progression which clearly recovered after shunting. These facts not only support the relationship between gait disturbance and hydrocephalus, but also stress the importance of a meticulous neurological examination in order to differentiate these entities, which can be overlapping, such as in the case we present.

Once the suspicion of hydrocephalus exist, MRI is mandatory to confirm the diagnosis and rule out other causes of gate disturbances, such as brain metastasis or paraneoplastic cerebellar degeneration [8-11]. If hydrocephalus is observed, carcinomatous meningitis must be excluded through contrast T1-weighted images and cytological examination of the CSF [12].

Our patient showed a clear and rapid improvement in gait performance after draining $30 \mathrm{~mL}$ of CSF through a lumbar puncture, similar to what occurs in patients with NPH and these benefits correlated with postsurgical outcomes. From this experience, we suggest that this method seems to be sufficient and safe in patients with docetaxel-induced hydrocephalus showing symptoms resembling NPH to assess whether the patient will respond or not to ventriculoperitoneal shunting [13].

Placement of a ventriculoperitoneal shunt led to a permanent improvement of gait performance which remained stable across years. The outcomes obtained provide evidence that, despite the superposition with polyneuropathy, NPH-like gait disturbance associated with docetaxel-induced hydrocephalus may have a favorable prognosis after CSF shunting.

It is true that the extremely low rate of hydrocephalus in patients treated with taxanes, added to the frequent use of these drugs in combination with other agents, makes a definitive pathophysiological linkage between the treatment with taxanes and the development of hydrocephalus difficult to establish. However, the development of hydrocephalus during or immediately after taxane-based chemotherapy, like in our patient, makes the relationship highly suspicious. The microtubule dysfunction induced by taxanes, destined to impair the mitotic spindle of neoplastic cells, is well known to affect microtubules of ciliated epithelia and therefore its function of removing and clearing particles and fluid over the epithelial surface $[14,15]$. It is possible that an impairment of ependymal cilia could lead in exceptional cases to a disruption of CSF clearance and circulation, predisposing to the development of hydrocephalus in a very small group of patients. In the case we present, a well-documented symptom of NPH such as progressive gait disturbance precisely after concluding a docetaxel- 


\section{Case Reports in Oncology}

based therapy, in an otherwise previously neurologically healthy patient, makes the assumption of a drug-induced hydrocephalus highly probable.

\section{Conclusions}

We present the rare case of hydrocephalus developed after a docetaxel-based chemotherapy for breast cancer. Although exceptional, this side effect should be ruled out in patients who have received docetaxel and present gait disturbances, before assuming the cause only related to polyneuropathy, since the misinterpretation of symptoms can lead to a delay in diagnosis and surgical treatment. In this regard, a meticulous neurologic examination added to a high level of suspicion is needed to avoid overseeing this complication. Brain MRI is mandatory to confirm the diagnosis as well as to rule out other causes of neurological deterioration in these patients. As with NPH patients, drainage of CSF through a lumbar puncture constitutes in our single-case experience a safe and effective method to evaluate the possible response to ventriculoperitoneal shunt. Furthermore, shunt of CSF seems to be effective in reverse gait disturbances and to provide permanent symptomatic relief.

\section{Statement of Ethics}

The article does not contain data to identify patients. The authors have no ethical conflicts to disclose.

\section{Disclosure Statement}

The authors declare that they have no conflict of interest.

\section{References}

-1 Jones SE, Savin MA, Holmes FA, O'Shaughnessy JA, Blum JL, Vukelja S, McIntyre KJ, Pippen JE, Bordelon JH, Kirby R, Sandbach J, Hyman WJ, Khandelwal P, Negron AG, Richards DA, Anthony SP, Mennel RG, Boehm KA, Meyer WG, Asmar L: Phase III trial comparing doxorubicin plus cyclophosphamide with docetaxel plus cyclophosphamide as adjuvant therapy for operable breast cancer. J Clin Oncol 2006;24:5381.

2 Docetaxel: Drug information. Lexicomp in UptoDate, 2017. https://www.uptodate.com/contents/docetaxel-drug-information.

3 Osmani K, Vignes S, Aissi M, Wade F, Milani P, Lévy BI, Kubis N: Taxane-induced peripheral neuropathy has good long-term prognosis: a 1- to 13-year evaluation. J Neurol 2012;259:1936-1943.

4 factmed.com 2017a. http://www.factmed.com/study-DOCETAXEL-causing-HYDROCEPHALUS.php.

5 factmed.com 2017b. http://factmed.com/study-PACLITAXEL-causing-HYDROCEPHALUS.php.

6 Sudarsky L, Simon S: Gait disorder in late-life hydrocephalus. Arch Neurol 1987;44:263.

-7 Stolze H, Kuhtz-Buschbeck JP, Drücke H, Jöhnk K, Illert M, Deuschl G: Comparative analysis of the gait disorder of normal pressure hydrocephalus and Parkinson's disease. J Neurol Neurosurg Psychiatry 2001;70:289.

-8 Waterhouse DM, Natale RB, Cody RL: Breast cancer and paraneoplastic cerebellar degeneration. Cancer 1991;68:1835-1841. 


\section{Case Reports in Oncology}

\begin{tabular}{l|l}
\hline Case Rep Oncol 2017;10:973-980 \\
\hline DOI: 10.1159/000481706 & $\begin{array}{l}\text { (c) 2017 The Author(s). Published by S. Karger AG, Basel } \\
\text { www.karger.com/cro }\end{array}$ \\
\hline
\end{tabular}

Serrano Sponton and Januschek: Docetaxel-Induced Hydrocephalus Presenting with Gait Disturbances Mimicking and Coexisting with Taxane-Associated Polyneuropathy

9 Jung JM, Kim S, Joo J, Shin KH, Gwak HS, Lee SH: Incidence and risk factors for leptomeningeal carcinomatosis in breast cancer patients with parenchymal brain metastases. J Korean Neurosurg Soc 2012;52:193-199.

10 Frisk G, Svensson T, Bäcklund LM, Lidbrink E, Blomqvist P, Smedby KE: Incidence and time trends of brain metastases admissions among breast cancer patients in Sweden. Br J Cancer 2012;106:18501853.

11 Tomasevic ZI, Rakocevic Z, Tomasevic ZM, Milovanovic Z, Inic M, Kolarevic D, Lukic V, Kovac Z: Incidence of brain metastases in early stage HER2 3+ breast cancer patients; is there a role for brain CT in asymptomatic patients? J BUON 2012;17:249-253.

12 Chamberlain MC, Kormanik PR: Carcinomatous meningitis secondary to breast cancer: predictors of response to combined modality therapy. J Neurooncol 1997;35:55-64.

13 Stolze H, Kuhtz-Buschbeck JP, Drücke H, Jöhnk K, Diercks C, Palmié S, Mehdorn HM, Illert M, Deuschl G: Gait analysis in idiopathic normal pressure hydrocephalus: which parameters respond to the CSF tap test? Clin Neurophysiol 2000;111:1678.

14 Boisvieux-Ulrich E, Laine MC, Sandoz D: In vitro effects of taxol on ciliogenesis in quail oviduct. J Cell Sci 1989;92:9-20.

15 Kavoi BM, Plendl J, Makanya AN, Ochieng' S, Kiama SG: Effects of anticancer drug docetaxel on the structure and function of the rabbit olfactory mucosa. Tissue Cell 2014;46:213-224. 


\section{Case Reports in Oncology}

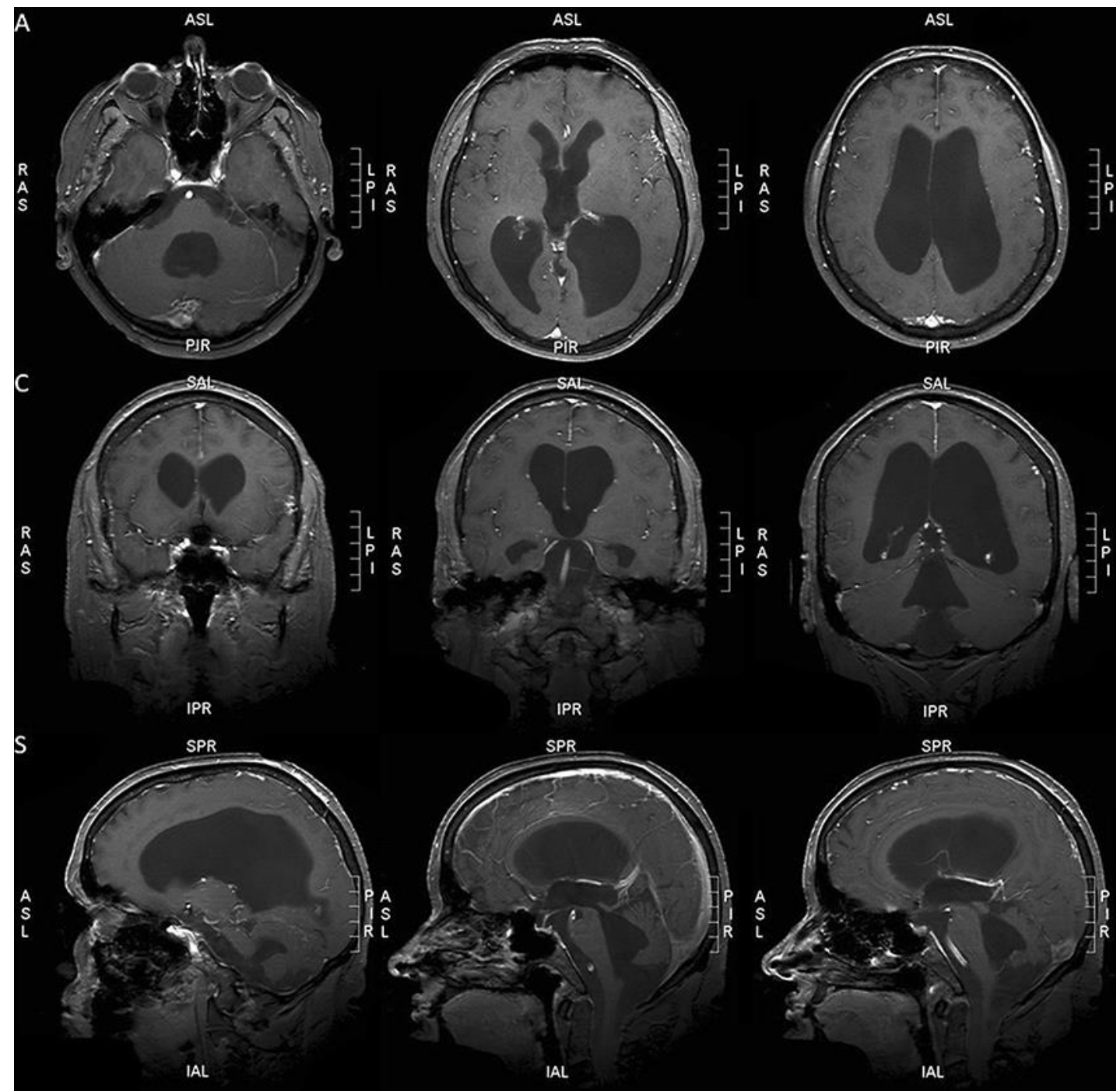

Fig. 1. Axial (A), coronal (C) and sagittal (S) preoperative contrast T1-weighted MRI showing a marked enlargement of the supra- and infratentorial ventricular system with a normally large subarachnoid space. No evidence of brain metastasis or spread of meningeal tumor was observed in brain MRI. 


\section{Case Reports in Oncology}

Table 1. Gait performance in $10-\mathrm{m}$ walking test and $360^{\circ}$ rotation at diagnosis, after lumbar puncture (LP) with drainage of $30 \mathrm{~mL} \mathrm{CSF}$ and after placement of a ventriculoperitoneal (VP) shunt

\begin{tabular}{|c|c|c|c|}
\hline & \multicolumn{2}{|c|}{10 -m walk } & \multirow{2}{*}{$\frac{360^{\circ} \text { rotation }}{\text { steps, } n}$} \\
\hline & steps, $n$ & time to complete, $\mathrm{s}$ & \\
\hline At diagnosis & 43 & 27 & 7 \\
\hline After $30 \mathrm{~mL}$ CSF release through LP & 25 & 13 & 3 \\
\hline After placement of a VP shunt & 23 & 11 & 3 \\
\hline
\end{tabular}

As depicted in the table, a notorious improvement in gait performance was observed after release of CSF through the LP, which remained stable after surgery. 